DOI: http://dx.doi.org/10.22484/2177-5788.2016v42n1p69-94

\title{
As onomatopeias na legendagem para surdos e ensurdecidos do filme Asterix et Obelix: Mission Cleopatre
}

\begin{abstract}
Ana Katarinna Pessoa do Nascimento
Resumo: O sexto álbum da série Astérix foi adaptado para o cinema em 2002, sob o título Astérix \& Obélix: missão Cleópatra e foi sucesso de público e crítica daquele ano. O lançamento do filme em DVD trouxe, em suas configurações, a legendagem para surdos e ensurdecidos (LSE). Por se tratar de obra adaptada de quadrinhos, alguns efeitos sonoros foram traduzidos por onomatopeias. Assim, a presente pesquisa tem como foco analisar se as onomatopeias são um meio adequado para a tradução de efeitos sonoros na LSE. Para tanto, etiquetou-se todas as traduções de efeitos sonoros do filme, que foram analisadas com o auxílio do software WordSmith Tools 5.0. Foi constatado que 60\% das legendas de efeitos sonoros no filme foram traduzidas por onomatopeias. Nessa situação, mesmo que o espectador surdo não decodificasse o conteúdo da legenda, a imagem poderia auxiliar na compreensão. No entanto, em algumas cenas, cuja legenda traduzia sons em off, o público-alvo poderia perder a significação do filme.
\end{abstract}

Palavras-chave: Legendagem para surdos e ensurdecidos. Onomatopeia. História em quadrinhos. Asterix \& Obelix.

\section{Onomatopoeia in the subtitling for the deaf and hard-of-hearing of the Astérix et Obélix: mission} Cleopatre movie

Abstract: The sixth album in the Asterix series was adapted for the big screen in 2002 under the title Asterix and Obelix: Mission Cleopatra and it was a great success of public and critic that year. The release of the film on DVD had, in its settings, subtitling for the deaf and hard-of-hearing (SDH). Since the movie is adapted from the comic book, some sound effects were translated by onomatopoeias. This paper examines whether the onomatopoeia is an appropriate means for translating sound effects on the SDH. Thus, each sound effect translation was labeled and analyzed with the WordSmith Tools 5.0 software. It was found that $60 \%$ of the sound effects in the movie were translated by onomatopoeias. In this situation, even if the deaf audience were not able to decode the contents of the subtitle, the image would aid in the comprehension. However, in some scenes in which there were sounds off screen, the target audience might miss the meaning of the film.

Keywords: Subtitling for the deaf and hard-of-hearing. Onomatopoeia. Comic books. Asterix \& Obelix. 
NASCIMENTO, Ana Katarinna do. As onomatopeias na legendagem para surdos e ensurdecidos do filme Asterix et Obelix.

\section{Introdução}

Esta pesquisa se deu a partir da coleta do corpus para a tese da pesquisadora, que busca encontrar uma linguagem própria da tradução de efeitos sonoros em três línguas (português brasileiro, inglês americano e francês europeu). Ao deparar com o filme Astérix \& Obélix: Mission Cleopatre foi grande a surpresa ao ver que muitos efeitos sonoros eram traduzidos por onomatopeias, algo que até então só havia sido mencionado na bibliografia a respeito da legendagem acessível a surdos e ensurdecidos, porém ainda não havia encontrado nenhum filme que as utilizasse. Daí, surgiu o interesse de pesquisar se as onomatopeias seriam eficazes para traduzir os efeitos sonoros, mesmo sendo imitação dos ruídos da natureza ou lembrando-os de alguma forma.

Para tanto, a metodologia escolhida foi a usada pela Linguística de corpus: as traduções de efeitos sonoros foram etiquetadas manualmente e analisadas por meio do software WordSmith Tools 5.0, que permite a busca pela etiqueta e a observação das legendas em contexto. Além disso, recorreu-se às imagens do filme e ao álbum dos quadrinhos, sempre que necessário.

Um breve estudo acerca da linguagem dos quadrinhos foi necessário, a fim de conhecer não apenas a linguagem do texto no qual o filme é baseado - o álbum Astérix et Cleopatre mas também, captar qual o papel da onomatopeia, sua origem e seus efeitos.

Além disso, também foram apontadas algumas considerações importantes sobre a legendagem em geral para compreender os seus parâmetros, bem como os parâmetros específicos da LSE e as questões acerca da onomatopeia como tradução de efeitos sonoros.

Nesse sentindo, o artigo em questão se propõe a analisar o uso das onomatopeias nas legendas para surdos e ensurdecidos (LSE) da adaptação fílmica francesa dos quadrinhos Astérix et Cleopatre, e se elas são eficientes para traduzir esse aspecto tão importante do cinema para o público surdo e ensurdecido. O presente artigo apresenta também uma breve introdução acerca do universo dos quadrinhos, bem como da legendagem para surdos e ensurdecidos. Posteriormente, apresenta-se a metodologia, que detalha como a pesquisa aconteceu, e, em 
NASCIMENTO, Ana Katarinna do. As onomatopeias na legendagem para surdos e ensurdecidos do filme Asterix et Obelix.

seguida, a análise dos dados. Finalmente, nas considerações finais, comentaremos os problemas e as soluções encontradas.

\section{Histórias em Quadrinhos (HQ)}

Para Bibe-Luyten (1985), a linguagem escrita e a imagem (ritmo visual) são os dois códigos de signos que estruturam as HQs. A primeira está presente em pelo menos duas formas: no balão e na onomatopeia. A autora entende que o balão é a principal invenção dos quadrinhos, pois possibilitou fluidez à ação, sendo, portanto, sua característica mais marcante. Cirne (1970, p. 16) considera o balão um solidificador da palavra, que pode passar de uma realidade linguística para uma realidade concreta, como em situações em que os personagens interagem com os balões (Em uma tirinha de Peanuts, por exemplo, o $\mathrm{Z}$ de um balão-cochilo cai no personagem Snoopy.).

Em geral, o balão contém a fala dos personagens e, nesse caso, está em sua forma mais comum. No entanto, conforme Bibe-Luyten (1985), é possível citar diversos tipos diferentes de balões que acompanham a história, participando também da imagem, tais como: balãopensamento, em formato nuvem; balão-berro, em formato pontiagudo; balão-medo, em formato tremido. Essas diferenças se dão no formato do balão; no entanto, há também diferenças quanto ao conteúdo ali presente. Por exemplo, segundo Cirne (1970), o balão-cochilo possui as letras ZZZ, indicando sono; o balão censurado possui algumas imagens, tais como cobras, lagartos e caveiras indicando palavrão; e até mesmo o balão personalizado, que é característico do personagem, assinalando sua personalidade. Na figura que segue, temos dois tipos de balões: o balão-fala, que representa a fala normal dos personagens e o balão-berro, que é pontudo, com as palavras em negrito (figura 1). Os quadrinhos de Asterix apresentaram uma inovação nesse sentido, uma vez que a fala de personagens em línguas estrangeiras era representada por caracteres gráficos (figura 4 , adiante). 
Figura 1 - Tipos de balões: balão-fala e balão-berro.

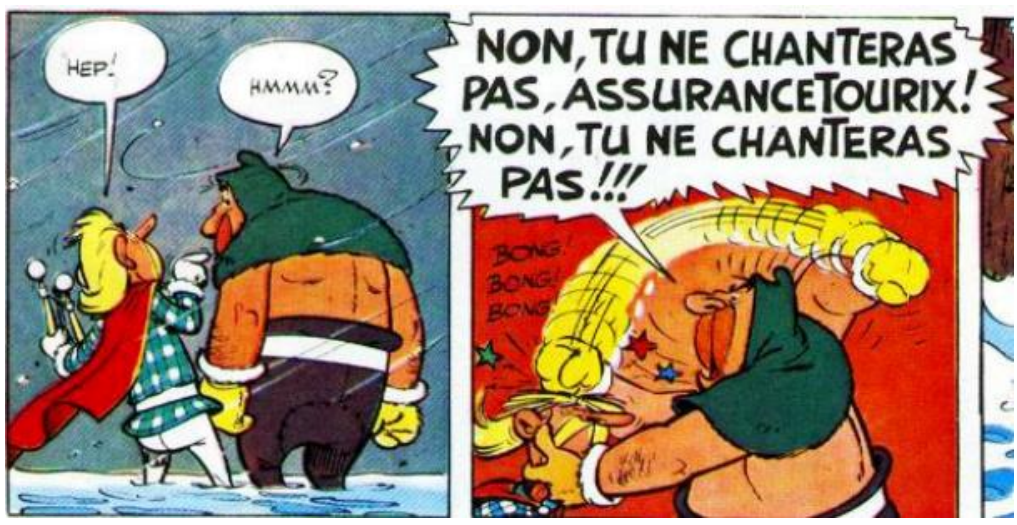

Fonte: GOSCINNY, René; UDERZO, Albert. Astérix et Cleopatre. Versão digital, 2014. Disponível em: <http://flo.vas.free.fr>. Acesso em: 14 de jul. 2015.

Como já mencionado, além do balão, as onomatopeias também compõem a linguagem escrita dos quadrinhos. Bibe-Luyten (1985) as classifica como representação do som nos quadrinhos e julga que oferecem beleza sonora a estes. Cirne (1970) entende que, além de sonoras, as onomatopeias são, também, visuais.

Apesar de alguns estudos apontarem para a primeira aparição de onomatopeias nos quadrinhos Sobrinhos do Capitão, em 1923, conforme (CIRNE, 1970), não se sabe ao certo quando elas passaram a integrar essa linguagem e a obter relevância. No entanto, é possível notar que a sua presença se concretizou nos quadrinhos norte-americanos e, por isso, a expressão onomatopeica está bastante enraizada na língua inglesa. Isso não impediu, no entanto, segundo Bibe-Luyten (1985), que autores das mais diversas línguas as utilizassem e até adaptassem as onomatopeias existentes ao seu próprio quadro linguístico, além de criarem novas e mais adequadas aos seus contextos. Sobre essa questão, Cirne (1970) entende que, apesar de atingirem uma linguagem universal, elas possuem modelos fonológicos próprios de cada língua.

Um rápido levantamento feito por Cirne (1970), sobre o número de onomatopeias utilizadas em 40 revistas, aponta que, em 1928 páginas, foram encontrados 1365 ruídos, dos quais 311 constituíam onomatopeias distintas. Tem-se, portanto, praticamente uma onomatopeia por página. Em outro levantamento, desta vez em quatro álbuns de Asterix (todos 
os que haviam sido lançados até 1970), de Goscinny e Uderzo, havia 374 ruídos no total, sendo 76 distintos nas 190 páginas. Glu-glu, onomatopeia que designa a deglutição de líquidos (muitas vezes fazendo referência à poção mágica consumida pelo personagem-título) aparece 4,9\% do total de vezes. Observa-se, portanto, que as onomatopeias desempenham importante papel nas histórias de Asterix.

Conforme Cirne (1970), nas boas histórias, as onomatopeias não são gratuitas, mas inseridas no contexto da narrativa, podendo ocupar não apenas o quadrinho por inteiro, mas atingir quadros vizinhos. Seu uso está para os quadrinhos como os ruídos bem utilizados estão para o cinema e constituem intensa comunicação sonora.

A outra componente das HQs é a imagem ou ritmo visual. Para Cirne (1970, p. 25), não basta um quadrinho bem desenhado, é preciso que haja uma estruturação em todos os quadrinhos, de modo que eles estejam relacionados entre si, com "beleza e equilíbrios formais, sem perder o sentido do ritmo, de movimento". O autor ainda afirma que as formas de movimento dependerão do veículo - jornal ou revista - pois, enquanto as tiras veiculadas nos jornais possuem um formato mais rígido, dificultando inovações no uso dos quadrinhos, a revista permite uma liberdade criativa no design dos quadros.

Vejamos agora qual a relação das onomatopeias com a legendagem para surdos e ensurdecidos (LSE), na seção a seguir. 
NASCIMENTO, Ana Katarinna do. As onomatopeias na legendagem para surdos e ensurdecidos do filme Asterix et Obelix.

\section{Legendagem para surdos e ensurdecidos (LSE)}

A legendagem, segundo Díaz Cintas e Remael (2007), é uma das modalidades de Tradução Audiovisual (TAV) e pode ser inter ou intralinguística: a primeira é aquela que traduz as falas de um produto audiovisual para outro idioma através do código escrito; já a segunda transfere o oral para o verbal dentro de um mesmo código linguístico e tem como público-alvo sujeitos surdos e ensurdecidos.

É importante notar que a LSE, conforme Araújo (2004), deve ser confeccionada a partir dos mesmos parâmetros técnicos da legenda interlinguística. São eles: marcação, condensação e segmentação. Além desses, a LSE possui ainda mais dois critérios: a identificação dos falantes e a tradução de músicas e efeitos sonoros. A identificação dos falantes é importante, pois muitas vezes os espectadores surdos não conseguem inferir a troca de turno de fala somente pela imagem. Além disso, a presença de dois ou mais sujeitos ao mesmo tempo em cena também pode dificultar a identificação de quem está falando.

Os efeitos sonoros na LSE são adicionados para preencher aspectos importantes relativos a informações acústicas não-verbais. Neves (2005) aponta que, em alguns casos, isso é feito por meio de uma operação intersemiótica, pois transforma mensagens não verbais em mensagens verbais, ou seja, as mensagens são transmutadas de um sistema para outro. Dessa forma, é importante que o tradutor seja um proficiente leitor de textos intersemióticos, pois precisa expressar em palavras escritas não apenas os diálogos, mas os efeitos sonoros que são integrados de forma natural ao filme.

Faz-se necessário um atento olhar à tradução dos efeitos sonoros de uma obra audiovisual, já que componentes acústicos não verbais colaboram para a construção de sentido e, sem eles, corre-se o risco de a obra audiovisual perder um dos seus elementos significadores. Algumas questões técnicas envolvem a tradução de efeitos sonoros, que podem ou não estar entre colchetes, em letras maiúsculas ou ainda em diferentes cores. Na França, de modo geral, os ruídos são legendados na cor vermelha, enquanto músicas são legendadas na cor magenta. Além disso, é muito comum utilizar-se o gênero musical para traduzir as músicas do filme (DIU, 2009), ou seja, ao invés de apenas indicar a presença da música ou de explicar qual a 
NASCIMENTO, Ana Katarinna do. As onomatopeias na legendagem para surdos e ensurdecidos do filme Asterix et Obelix.

função da música dentro do enredo, os franceses optam por indicar o seu gênero musical: romântico, jazz, folk, funk, etc (figura 2). Díaz Cintas e Remael (2007) entendem que quando a letra da música não é relevante para a trama, não há necessidade de ser traduzida, a menos que haja tempo para tal. Porém, se a mensagem da música for importante para a compreensão da obra, a letra deve ser legendada, como geralmente ocorre em musicais.

Figura 2 - Legenda com o gênero musical Rythm \& Blues.

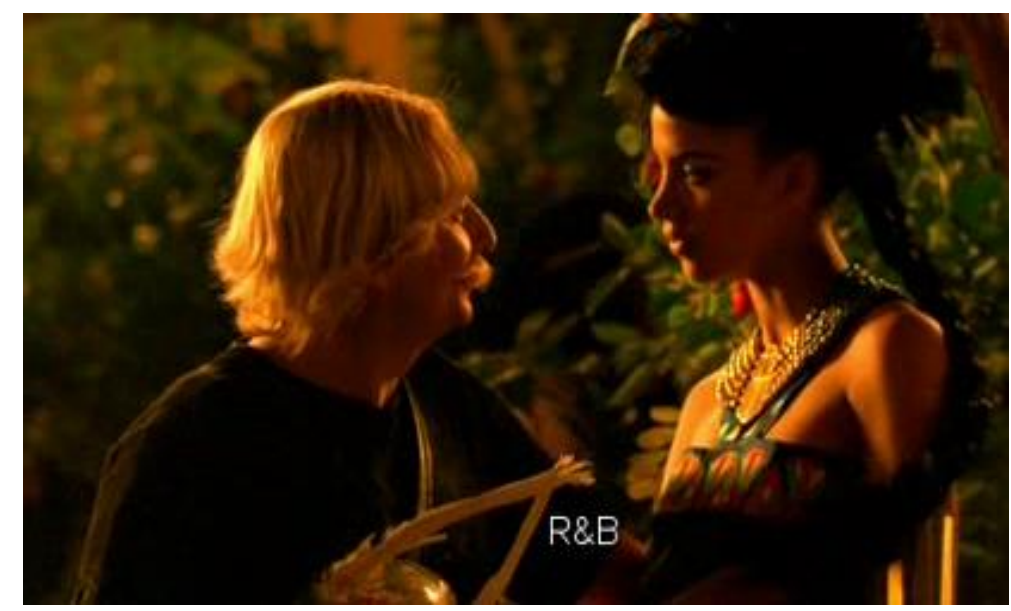

Fonte: ASTÉRIX \& Obélix: mission Cleopatre. Direção: Alain Chabat. França, Itália: TF1 Films Productions. 2002. Disponível em: <http://streamcomplet.com/asterix-et-obelix-mission-cleopatre/>. Acesso em: 14 jul. 2015.

O uso da onomatopeia como alternativa para a tradução de efeitos sonoros é bastante polêmica e ainda não há consenso na bibliografia acerca da LSE. Neves (2005) cita o guia CMP (Captioned Media Program), que sugere o uso da pontuação e da onomatopeia para expressar repetição e/ou intensidade. A autora cita também Baker et al. (1984), que propõe o uso de onomatopeias conhecidas na tradução de efeitos sonoros. No entanto, ressalta que, em alguns casos, é necessário distinguir alguns ruídos que podem ter a mesma onomatopeia - bombas e balões estourando, por exemplo - sendo necessário descrever o som. Outros guias de legendagem falam em uso da onomatopeia em programas infantis e de comédia. Esse parâmetro pode ter sido o utilizado no corpus de estudo do presente trabalho, pois trata-se de adaptação 
de HQ, cujo gênero é o humor. Na próxima seção, são apresentados os passos metodológicos da presente pesquisa.

\section{Metodologia}

O corpus do presente trabalho é composto pelo álbum Astérix et Cleopatre ${ }^{l}$ e pelo filme Astérix \& Obélix: Mission Cleopatre (2002).

Astérix et Cleopatre é o sexto álbum da série em quadrinhos Astérix, de Réné Goscinny (texto) e Albert Uderzo (desenho), e foi lançado em 1965 com uma tiragem de 10.000 exemplares. Os autores tiveram a ideia para essa história após assistirem ao filme Cleopatra (1963), estrelado por Elizabeth Taylor. O álbum inteiro possui muitas referências a essa obra, como, por exemplo, piadas em relação à beleza de Cleópatra, sua constante troca de figurino, seu temperamento difícil e, ainda, alguns elementos gráficos, como a capa do álbum, que remete ao pôster do filme.

\footnotetext{
${ }^{1}$ A edição aqui analisada foi a digital de 2014.
} 
NASCIMENTO, Ana Katarinna do. As onomatopeias na legendagem para surdos e ensurdecidos do filme Asterix et Obelix.

\section{Figura 3 - Capa do álbum Astérix et Cleopatre.}

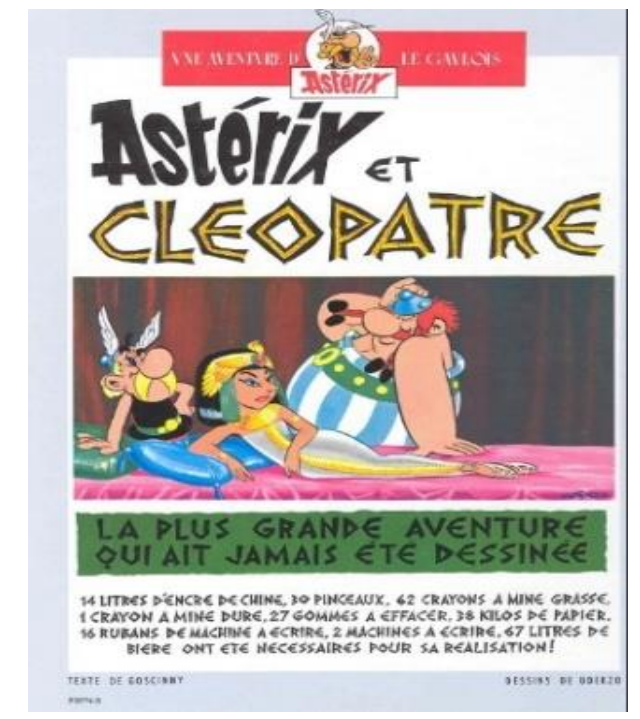

Fonte: GOSCINNY, René; UDERZO, Albert. Astérix et Cleopatre. Versão digital, 2014. Disponível em: <http://flo.vas.free.fr >. Acesso em: 14 de jul. 2015.

A trama tem início após Cleópatra ouvir de Júlio César que os egípcios não construíram nada de relevante desde as pirâmides, enquanto os romanos constroem templos magníficos. A rainha decide, então, apostar com ele que seu povo seria capaz de erguer um suntuoso palácio em apenas três meses. Para executar tal tarefa, a rainha egípcia chama o arquiteto Numérobis. $\mathrm{O}$ arquiteto, com medo de ser jogado aos crocodilos caso falhe em sua missão, busca ajuda do mago gaulês Panoramix, druida que possui uma poção mágica, capaz de dar grande força àqueles que a tomam. O mago parte ao Egito juntamente com seus amigos Astérix, Obélix e o cachorro Ideiafix. Já no Egito, os gauleses, então, distribuem a poção mágica para os trabalhadores do palácio que, dotados de superforça, avançam muito rapidamente nos trabalhos. No entanto, diversas vezes são impedidos pelos romanos, que querem o fracasso da construção, e também pelo arquiteto Amonbofis, concorrente de Numérobis. Por fim, o castelo é construído e César pede desculpas à rainha. Numérobis é recompensado com ouro e os gauleses com manuscritos valiosos da biblioteca de Alexandria. Como é de praxe nas histórias de Astérix e Obélix, ao retornarem ao seu país, ocorre um grande banquete. 
NASCIMENTO, Ana Katarinna do. As onomatopeias na legendagem para surdos e ensurdecidos do filme Asterix et Obelix.

Em alguns momentos, as falas de personagens estrangeiros, mais precisamente não gauleses, são reproduzidas através de caracteres especiais - no caso dos egípcios, por exemplo, os caracteres imitam os hieróglifos (figura 4). Posteriormente, as falas passam a ser em língua francesa, como as dos demais personagens, o que os autores chamaram de "recurso de dublagem", uma brincadeira que eles fizeram para justificar que personagens estrangeiros "falem" em francês. Um levantamento mostrou que o álbum possui 88 onomatopeias, distribuídas em 34 das 44 páginas do álbum, o que perfaz, em média, 1,9 onomatopeias por página.

Figura 4 - Caracteres especiais na fala de personagens estrangeiros.

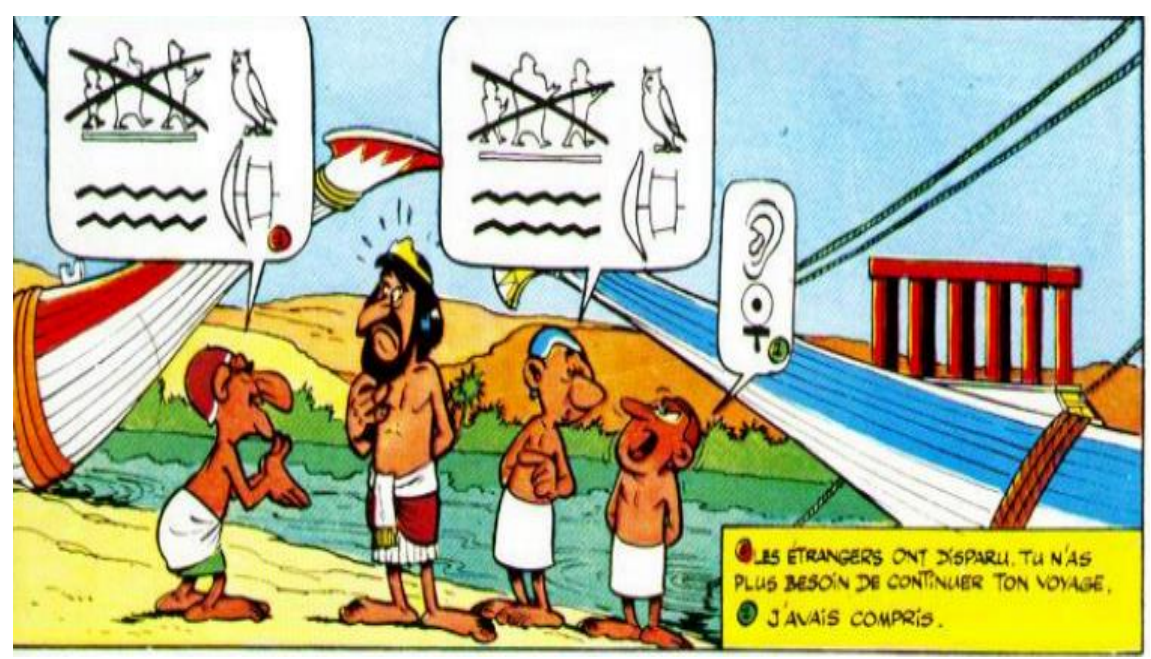

Fonte: GOSCINNY, René; UDERZO, Albert. Astérix et Cleopatre. Versão digital, 2014. Disponível em: <http://flo.vas.free.fr>. Acesso em: 14 de jul. 2015.

Esse álbum possui duas adaptações: a primeira, para desenho animado, em 1968, produzido por um estúdio especializado em adaptações de HQs franco-belgas, o Belvision. A animação foi feita pelos próprios autores dos quadrinhos. Apenas em 2002, foi adaptado em live-action, ${ }^{2}$ e constitui o segundo filme da série Astérix \& Obélix para o cinema. Dirigido por

\footnotetext{
2 Filmes que não são animação.
} 


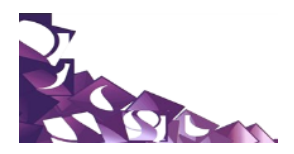

NASCIMENTO, Ana Katarinna do. As onomatopeias na legendagem para surdos e ensurdecidos do filme Asterix et Obelix.

Alain Chabat, o filme foi um sucesso de público e de crítica na França: é o $4^{\circ}$ filme francês mais visto na França e foi o $1^{\circ}$ no ano de seu lançamento. O elenco é composto por famosos artistas franceses, tais como Monica Bellucci e Gérard Depardieu.

Figura 5 - Encarte do DVD do filme Astérix \& Obélix: Mission Cleopatre.

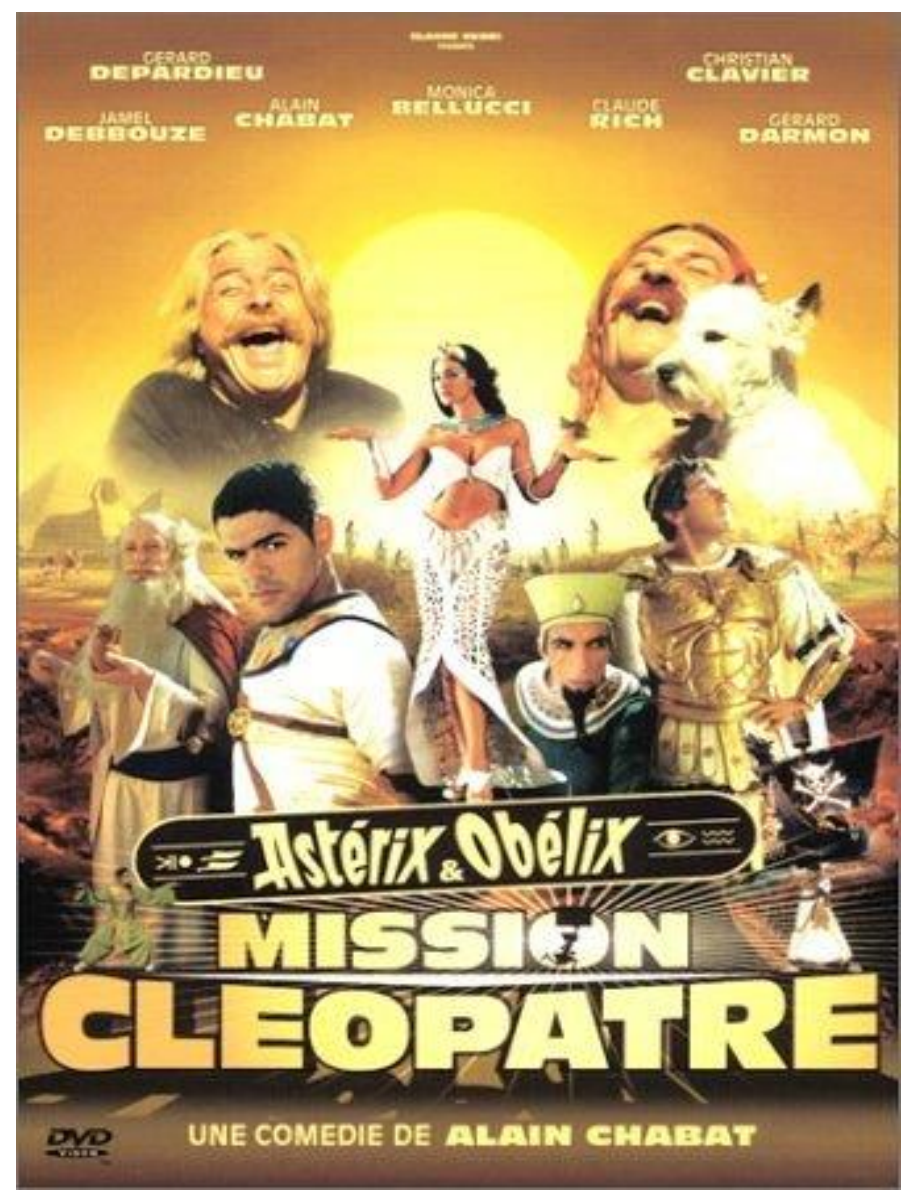

Fonte: ASTÉRIX \& Obélix: mission Cleopatre. Direção: Alain Chabat. França, Itália: TF1 Films Productions. 2002. Disponível em: <http://streamcomplet.com/asterix-et-obelix-mission-cleopatre/>. Acesso em: 14 jul. 2015. 
O filme conta a mesma história do álbum, porém com algumas mínimas diferenças como, por exemplo, o papel de destaque atribuído ao arquiteto Amonbofis, que se torna o grande vilão da história. Além disso, há o interesse amoroso de Astérix por uma das damas da rainha Cleópatra.

A metodologia utilizada pela Linguística de corpus, tomada como metodologia no presente trabalho, investiga textos em formato eletrônico. Primeiramente, foi acessado o site Amazon e se buscou por Astérix \& Obélix: Mission Cleopatra, onde foi possível constatar que o DVD do filme possui legendagem para surdos e ensurdecidos. Em seguida, buscou-se pela legenda no site opensubtitles.org, que disponibiliza arquivos de legenda. $\mathrm{O}$ arquivo encontrado no formato srt foi, então, baixado para o computador da pesquisadora que, posteriormente, assistiu ao filme com as legendas, para verificar se estavam completas ou com algum tipo de problema. Não foi verificado nenhum problema com a legenda baixada do site, sendo, então, considerada apta a ser analisada neste estudo.

Seguiu-se a etapa de etiquetagem das legendas. As etiquetas são as mesmas utilizadas em Nascimento e Araújo (2015, p. 206), com o acréscimo de <onom>, que ocorre sempre que o efeito sonoro foi traduzido por uma onomatopeia. 
NASCIMENTO, Ana Katarinna do. As onomatopeias na legendagem para surdos e ensurdecidos do filme Asterix et Obelix.

\begin{tabular}{c|c|c}
\multicolumn{2}{c}{ Quadro 1 - Etiquetas } \\
\hline Tipo de som & Etiqueta & Exemplo \\
\hline Efeito Sonoro & <es $>$ & Musique Romantique \\
\hline Música de fosso & $<$ mus_fosso $>$ & Musique Militaire \\
\hline Música em tela & <mus_tela $>$ & Musique d'ascenseur \\
\hline Onomatopeia & <onom> & Paf! \\
\hline Som causado pelo homem & <som_hom> & Déglutition \\
\hline Som causado por animais & <som_anim> & Cri de dromadaire \\
\hline Som causado por objeto & <som_obj> & Vase Brisé \\
\hline Som da natureza & <som_nat> & Vent \\
\hline Som ficcional & <som_ficc> & Bourdonnement \\
\hline
\end{tabular}

Fonte: NASCIMENTO, Ana Katarinna Pessoa do; ARAÚJO, Vera Lucia Santiago. Tradução de efeitos sonoros na legendagem para surdos e ensurdecidos. In: ZAVAGLIA, Claudia: STUPIELLO, E.N.A. Tendências contemporâneas dos estudos da tradução. São José do Rio Preto: UNESP, 2015. p. 206.

Os dados foram analisados por meio do software WordSmith Tools versão 5.0. Apesar de não ser a versão mais recente do programa, atendeu bem ao propósito deste estudo. $\mathrm{O}$ programa possui três ferramentas. São elas: WordList, que gera uma lista das palavras presentes no corpus; KeyWords, que apresenta a lista de palavras-chave do corpus em relação a um corpus de referência, e Concord, que é um concordanciador, mostrando as palavras de busca em contexto. Das três ferramentas disponíveis, foi utilizada apenas o Concord.

As palavras de busca foram as etiquetas; dessa forma, foi possível ver todas as legendas de uma mesma etiqueta juntas. Isso possibilitou a quantificação das ocorrências de cada etiqueta, mas também a observação das legendas, no intuito de buscar padrões de comportamento no que diz respeito à tradução de músicas e efeitos sonoros e ao uso da onomatopeia.

Para facilitar a visualização e análise dos dados, a pesquisa foi reorganizada pela primeira palavra à direita das etiquetas, em ordem alfabética, aproximando legendas

\footnotetext{
${ }^{3}$ Música de fosso é aquela que apenas os espectadores ouvem; enquanto música de tela é aquela que está presente na ação da cena, ou seja, os personagens em tela também podem ouvi-la.
} 
semelhantes. Assim, a pesquisadora pôde observar, de forma mais prática, o contexto das legendas.

A pesquisa recorreu ao filme para analisar as traduções dos efeitos sonoros, pois é importante observá-los integrados ao todo fílmico e também à HQ, com o intuito de entender as escolhas do tradutor. Para compreender melhor os significados das onomatopeias encontradas, foram consultados dois sites (um francês e um americano) dedicados a descrever significados de onomatopeias. São eles: Les Onomatopées (2015) e Onomatopoeia List (2015).

A seção 4, a seguir, descreve a análise de dados.

\section{Resultados}

O corpus é composto por 1824 legendas, sendo que destas, 258 contém uma ou mais traduções de efeitos sonoros, ou seja, aproximadamente 14\% das legendas. Dessas legendas de efeitos sonoros, 165 são onomatopeias, ou seja, 64\% das legendas de efeitos sonoros são traduzidas por onomatopeias no filme Asterix \& Obelix: Mission Cléopatra. Vejamos nas imagens a seguir: 
NASCIMENTO, Ana Katarinna do. As onomatopeias na legendagem para surdos e ensurdecidos do filme Asterix et Obelix.

Figura 6 - Total de legendas ${ }^{4}$.

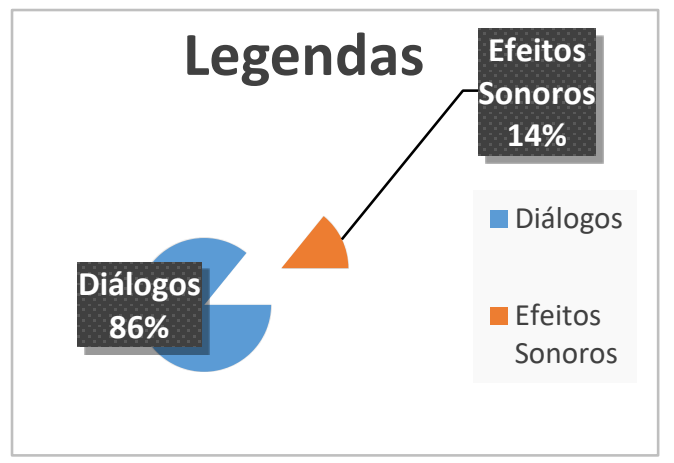

Fonte: Elaboração própria.

Figura 7 - Número de legendas de efeitos sonoros.

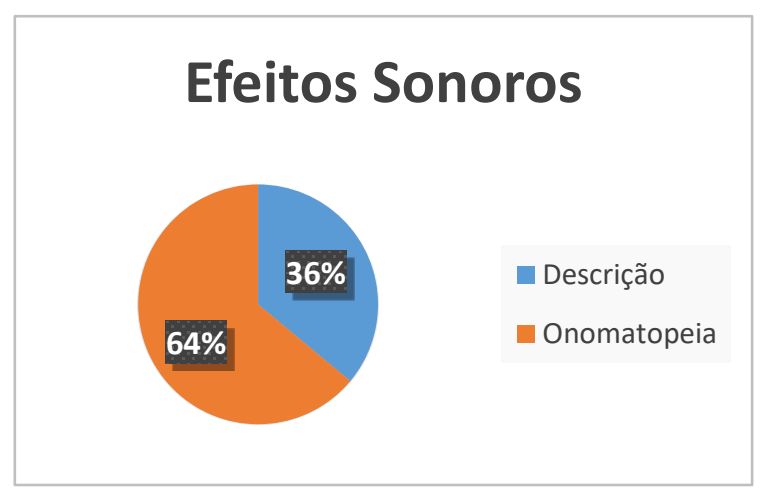

Fonte: Elaboração própria.

\footnotetext{
${ }^{4}$ Neste trabalho, por se tratar de um único corpus, os dados serão apresentados em números absolutos, de acordo com Baker (2006).
} 
Para obter o número total de cada etiqueta, é necessário apenas fazer uma busca por cada uma delas, pois o software informa o total de vezes que a palavra buscada (no caso do presente trabalho, as etiquetas) aparece no corpus. Assim, feita a busca pela etiqueta <som_hom>, por exemplo, foram encontradas 167 ocorrências no total. Para saber quais das 167 seriam traduções por onomatopeias, fez-se a busca <som_hom><onom>; assim, o programa procuraria apenas quando as duas etiquetas aparecem juntas, ou seja, somente quando o som causado pelo homem foi traduzido por onomatopeia. Essa segunda busca gerou 129 resultados. Ou seja, do total de 167 efeitos sonoros causados pelo homem, 129 foram traduzidos por onomatopeia e, por exclusão, apenas 38 pela descrição do som.

Esse procedimento foi repetido para cada uma das etiquetas, de forma a quantificar o total de efeitos sonoros em cada categoria, bem como o total de vezes que foram traduzidos por onomatopeia e por descrição. O quadro abaixo (quadro 2) mostra, em sua segunda coluna, o número de legendas em cada categoria de som traduzidos e, na terceira coluna, o número de legendas em que o som foi traduzido por uma onomatopeia. 
NASCIMENTO, Ana Katarinna do. As onomatopeias na legendagem para surdos e ensurdecidos do filme Asterix et Obelix.

Quadro 2 - Números de Efeitos Sonoros ${ }^{5}$

\begin{tabular}{c|c|c|c}
\hline Categoria & Descrição & Onomatopeia & Quantidade Total \\
\hline Música de Fosso & 36 & 0 & 36 \\
\hline Música de Tela & 3 & 0 & 3 \\
\hline Som causado por animais & 9 & 12 & 21 \\
\hline Som causado por objeto & 7 & 17 & 24 \\
\hline Sons causados pelo homem & 38 & 129 & 3 \\
\hline Som da natureza & 1 & 2 & 6 \\
\hline Som Ficcional & 1 & 5 & 260 \\
\hline Total & 95 & 165 & 3 \\
\hline
\end{tabular}

Fonte: Elaboração própria.

Nesse trabalho, utilizamos apenas os efeitos sonoros não musicais. De acordo com Nascimento e Tagnin (2014), os efeitos sonoros não musicais mais frequentemente traduzidos pelos filmes franceses são os produzidos pelo homem e por objetos; esses resultados são corroborados nesta pesquisa, pois são duas as categorias de efeitos sonoros não musicais que possuem maior número de ocorrências de efeitos sonoros (167 de sons causados pelo homem e 24 de sons causados por objetos) e também de traduções por onomatopeia (129 e 17, respectivamente).

Ainda de acordo com Nascimento e Tagnin (2014), isso ocorre porque esses sons geralmente causam algum tipo de atitude dos personagens em tela e, se não fossem legendados, os surdos e ensurdecidos poderiam perder uma informação importante para a trama. Muitos dos sons produzidos pelo homem são referentes a gritos de dor dos personagens e foram traduzidos por onomatopeias como “Aaah" ou “Aïe”. É importante notar que “Aaah": 1) pode ter

\footnotetext{
${ }^{5}$ Importante notar que o número de efeitos sonoros difere do número de legendas de efeitos sonoros, visto que uma mesma legenda pode apresentar mais de um efeito. É o caso, por exemplo, da legenda 178: “Bêêê !!! Scrunch! Scrunch!” que possui duas traduções de efeitos sonoros diferentes: Bêêê!! Corresponde ao balir de uma cabra e Scrunch Scrunch! à deglutição.
} 
diferentes grafias $\left.{ }^{6} ; 2\right)$ pode indicar diversos - sentimentos diferentes - dor, surpresa, realização e até prazer (ONOMATOPOEIALIST, 2015). Assim, o espectador precisaria reconhecer a onomatopeia em suas diferentes grafias e se guiar pela imagem para compreender com qual sentido ela foi utilizada no filme. Ou seja, em vez de ter a legenda como mais um suporte para compreensão, ele teria unicamente a imagem para decodificar o significado da onomatopeia e a trama do filme.

Essa onomatopeia raramente aparece no álbum e, em geral, está representada dentro do balão, por se tratar de fala. Muitas vezes, para representar a dor do personagem, o álbum aposta em um conhecido recurso visual, as estrelas coloridas saindo do personagem, como é possível ver na figura 8 abaixo.

Figura 8 - estrelas coloridas representando a dor dos personagens.

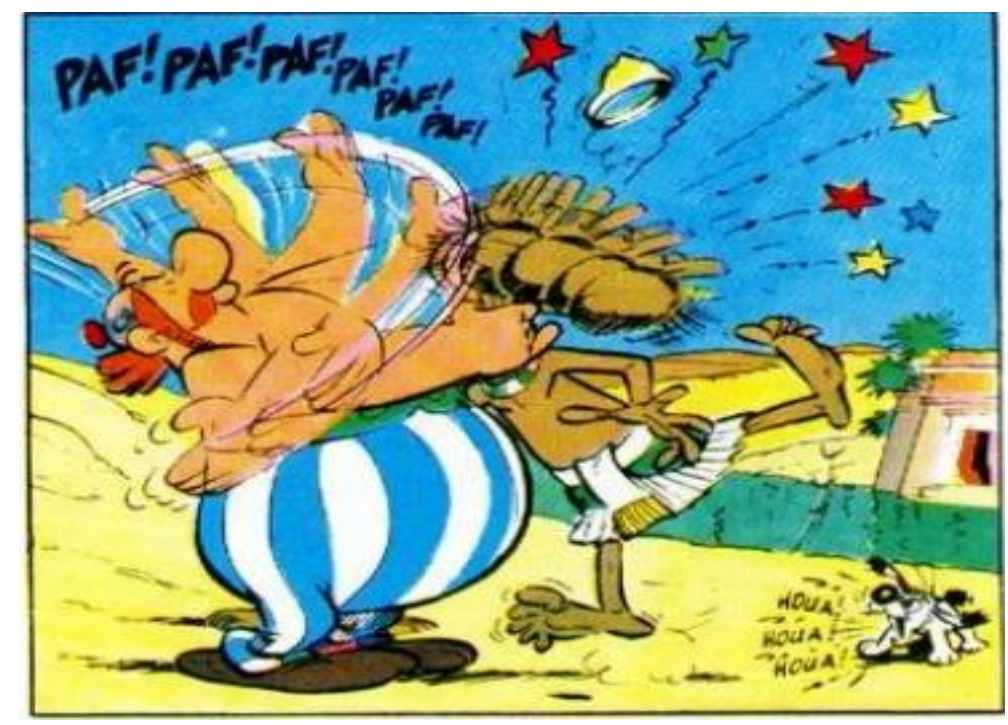

Fonte: GOSCINNY, René; UDERZO, Albert. Astérix et Cleopatre. Versão digital, 2014. Disponível em: <http://flo.vas.free.fr>. Acesso em: 14 de jul. 2015.

\footnotetext{
${ }^{6}$ No filme que compõe o corpus, essa onomatopeia apareceu 12 vezes, com cinco diferentes grafias: Aaaaah!, Aaaah!, Aaah!, Ah!, Ahhhh!
} 
A onomatopeia Aïe é frequente no corpus de estudo e aparece 6 vezes; também indica dor de personagem, porém as situações de sua inserção são bastante particulares, pois são usadas em tom cômico, quando os personagens fizeram por merecer estar na situação de dor, já que se colocaram em conflito com os heróis.

As onomatopeias para risadas dos personagens tampouco possuem grafia fixa, mas a mais comum é ha ha ha!. Para aumentar a intensidade da risada, aumenta-se o número/a quantidade de ha; além disso, nem sempre o ponto de exclamação está presente, ou pode estar presente após cada ha. No entanto, é possível apontar outras formas de escrita, como he he he ou hi hi hi. Em geral, he he he significam risadas do vilão e hi hi hi, risadas tímidas e/ou jocosas. (ONOMATOPOEIASLIST, 2015).

No filme, não foi feita distinção entre risadas verdadeiras e risadas sarcásticas, que foram grafadas como ha, ha, ha!. Já para risadas jocosas, utilizou-se a grafia hin, hin!, ou hin, hin, hin!. Houve, ainda, o riso de Amonbofis, o vilão, que ri de maneira bastante característica, sibilante. A onomatopeia para esse som foi Tss, aumentando o número de "s" de acordo com a intensidade da risada (figura 9). Essa onomatopeia não está listada nos sites de consulta, tampouco é usada nos quadrinhos. Por ser de difícil compreensão, seu significado é depreendido apenas pelo contexto: em uma das cenas, por exemplo, um dos personagens pede a Amonbofis que não ria dessa forma, pois o assusta.

Ainda sobre os risos, em um momento do filme, em vez de serem traduzidas por onomatopeias, o tradutor optou pela descrição do som rires, sendo, portanto, bastante arbitrária a escolha de quais sons são traduzidos ou não por onomatopeias. 
Figura 9 - Risos de Amonbofis.

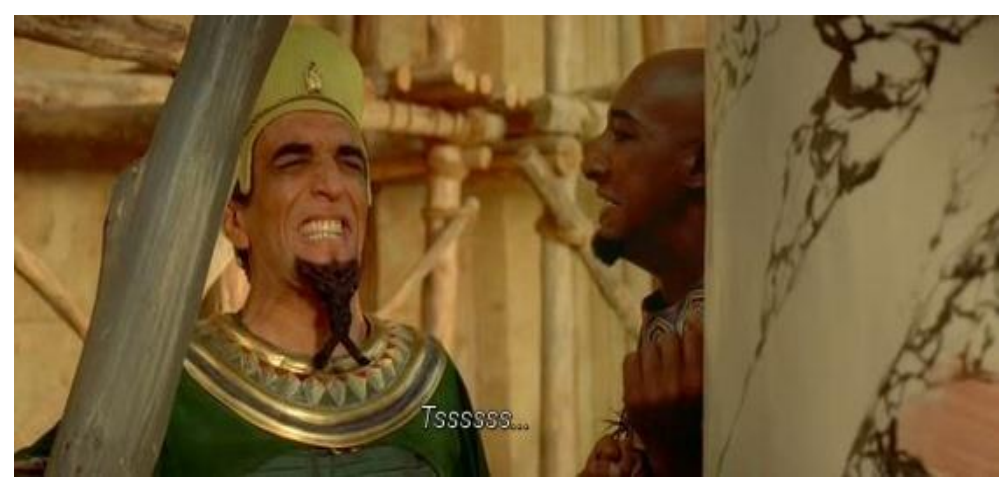

Fonte: ASTÉRIX \& Obélix: mission Cleopatre. Direção: Alain Chabat. França, Itália: TF1 Films Productions. 2002. Disponível em: 〈http://streamcomplet.com/asterix-et-obelix-mission-cleopatre/>. Acesso em: 14 jul. 2015.

Nos quadrinhos de Asterix, a onomatopeia Paf é bastante recorrente e, até, característica. Corresponde ao som de soco e/ou tapas. O legendista do filme optou por manter a mesma onomatopeia nessas situações. Por ser uma onomatopeia bastante familiar (aparece listada nos sites de consulta), os contextos em que aparece não deixam dúvidas quanto ao que representa.

Por fim, ainda sobre os ruídos causados pelo homem, é preciso salientar o caso de falantes de língua estrangeira. Os quadrinhos de Asterix têm como uma de suas características o emprego de caracteres nos balões para demonstrar o uso de língua estrangeira, sendo que o diálogo mesmo é posto em nota de rodapé (ver fgura 4). No caso do álbum, o idioma estrangeiro frequente é o egípcio e os caracteres são parecidos com hieróglifos. Já na legendagem do filme, foi utilizado apenas um traço “-” para indicar a fala em outro idioma; nessas situações, só é possível entender o conteúdo quando um outro personagem o repete em francês. Em apenas uma legenda (Japonais), foi indicado que língua estrangeira era falada. Esse caso difere dos demais, pois não se tratava de diálogo importante para a trama tendo sido inserido para causar humor - baseado no estereótipo de que os turistas japoneses estão por toda parte; no caso, até mesmo no Egito Antigo (figura 10). 
NASCIMENTO, Ana Katarinna do. As onomatopeias na legendagem para surdos e ensurdecidos do filme Asterix et Obelix.

Figura 10 - Descrição de fala estrangeira

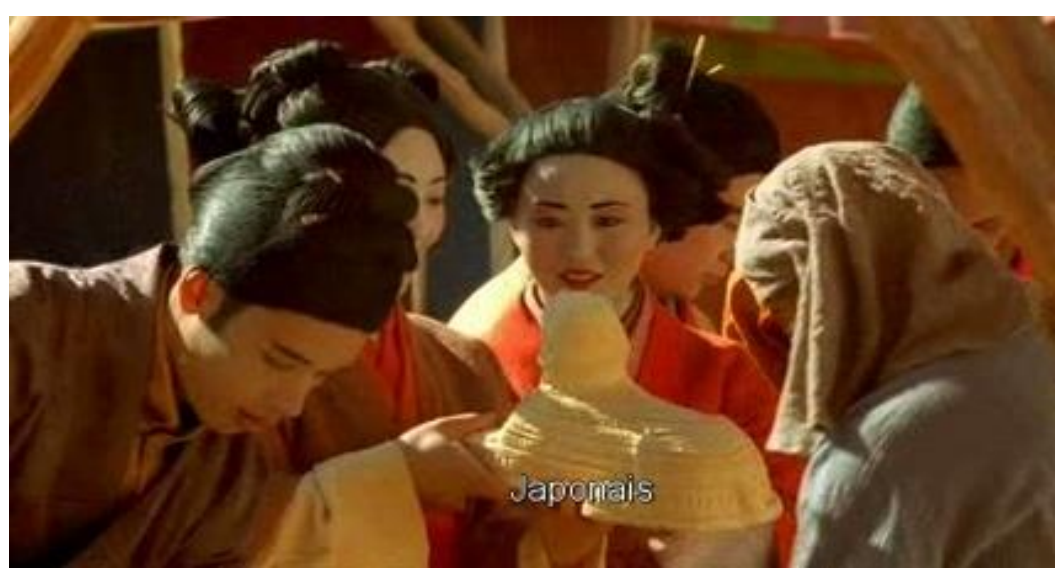

Fonte: ASTÉRIX \& Obélix: mission Cleopatre. Direção: Alain Chabat. França, Itália: TF1 Films Productions. 2002. Disponível em: 〈http://streamcomplet.com/asterix-et-obelix-mission-cleopatre/>. Acesso em: 14 jul. 2015.

Os ruídos causados por objeto são a terceira categoria mais frequente do corpus. A onomatopeia que mais aparece é blub blub, com um blub a mais em algumas ocorrências. Esse som corresponde ao da poção mágica sendo preparada e, por isso, é bastante importante: é a fonte da força de Astérix e Obélix, e é por causa dela que Numérobis vai procurar os gauleses para ajudá-lo. No entanto, essa não é a onomatopeia recorrentemente utilizada para o som de liquido fervendo: o site Onomatopoiea List (o site francês não apresenta onomatopeias para esse som) indica glub glub para esse fim, o que comprova novamente a arbitrariedade no uso da onomatopeia. Importante ressaltar, ainda, que, embora nos quadrinhos a poção mágica não seja acompanhada de nenhuma onomatopeia, no filme, ela é indispensável para dar ênfase a essa parte significativa da história. Em uma das vezes em que aparece, porém, essa onomatopeia não se refere à poção mágica, e busca causar humor, pois Panoramix apenas prepara uma sopa.

Outro som causado por objeto muito frequente é boum; o site Les Onomatopeés o classifica como explosão. No filme, não corresponde ao som de explosões, mas a grandes pedras sendo catapultadas, ou jogadas ao chão. Nos quadrinhos, para esse som, os autores optaram pelo uso de paf e bong, ao invés de boum, que não aparece em nenhum momento. 
Por fim, o som de algo sendo quebrado é bastante recorrente tanto nos quadrinhos quanto no filme. Enquanto o primeiro utiliza sempre a onomatopeia crac, podendo variar de intensidade aumentado o número/a quantidade de "a"s, no segundo, a tradução do som também se dá pela onomatopeia (porém, crac aparece apenas uma vez) e pela descrição do som: fracas (que significa estrondo, barulho violento, não especificando bem qual a fonte do som) e vase brisé (vaso quebrado, especificando a fonte do som). Portanto, novamente, fica claro que não há um padrão no uso da onomatopeia, sendo que sons semelhantes podem ser traduzidos pela descrição do som ou pela onomatopeia.

Nessa seção foram analisadas as traduções de efeitos sonoros na legendagem do filme Astérix \& Obélix: Mission Cleopatre. Em resumo, por se tratar de adaptação fílmica de quadrinhos, a tradução de efeitos sonoros utilizou onomatopeias para alguns sons. No entanto, não foi encontrado um padrão, sendo que sons semelhantes foram ora traduzidos por onomatopeias, ora pela sua descrição (forma mais recorrente em outros filmes). Entendemos também que a arbitrariedade tanto na ortografia da onomatopeia quanto no seu significado (pois, como visto, uma onomatopeia pode ser escrita de diferentes formas e corresponder a diferentes sentimentos, ruídos e ações) poderia prejudicar a compreensão do espectador surdo, que teria de se apoiar unicamente nas imagens para compreender a trama fílmica e decodificar a legenda, caso não fosse familiarizado com a linguagem das onomatopeias. Além disso, muitas onomatopeias que aparecem na LSE não aparecem nos quadrinhos ou foram usadas de forma diferente, não apresentando correspondência total entre um e outro.

\section{Considerações finais}

Esta pesquisa teve como escopo analisar se as onomatopeias são um meio adequado para a tradução de efeitos sonoros na legendagem para surdos e ensurdecidos (LSE). Para tanto, foram analisadas as legendas do filme Astérix \& Obélix: Mission Cleopatre, pois, por se tratar de adaptação fílmica do álbum de quadrinhos Astérix et Cleopatre, o legendista optou por traduzir alguns efeitos sonoros por onomatopeias. 
NASCIMENTO, Ana Katarinna do. As onomatopeias na legendagem para surdos e ensurdecidos do filme Asterix et Obelix.

A metodologia utilizada pela Linguística de corpus se mostrou adequada, pois possibilitou que as legendas de efeitos sonoros, após o processo de etiquetagem manual, fossem listadas em ordem alfabética de acordo com sua categoria, permitindo não apenas a quantificação do número de legendas de efeitos sonoros, mas também a visualização de padrões na tradução desses efeitos. Assim, mostrou-se que, como em outros estudos, segundo Nascimento e Tagnin (2014), o maior número de traduções de efeitos sonoros não musicais ocorreu nas categorias 'som causados pelo homem' e 'som causados por objetos', isso porque, de forma geral, são esses sons que provocam maior reação por parte dos personagens na trama. Além disso, também foram quantificados os efeitos sonoros traduzidos pela descrição do som e por onomatopeias, bem como foi analisado o uso de cada uma em contexto.

Todavia, alguns outros recursos foram necessários a fim de que a análise dos dados fosse pertinente e eficaz: a falta de contexto, em alguns casos, não permitiu saber com segurança qual a fonte do som no filme ou seu significado, sendo necessário recorrer ao filme para esclarecer a questão. Além disso, o programa utilizado não é compatível com imagens e, sempre que foi necessário recorrer aos quadrinhos, foi preciso procurar pelas onomatopeias de forma manual.

Por questões de tempo e espaço, não foi possível analisar todas as categorias e todos os sons, porém o estudo de duas categorias - sons causados pelo homem e sons causados por objetos - foi bastante efetivo, pois foram encontrados diversos fatores que devem ser levados em consideração ao traduzir efeitos sonoros pelas onomatopeias na legendagem para surdos e ensurdecidos. São eles:

1) Procurar estabelecer um padrão de quais efeitos sonoros serão traduzidos por onomatopeias e quais serão traduzidos da forma convencional, ou seja, pela descrição do som. Nas legendas do filme analisado, muitos sons semelhantes foram traduzidos das duas formas, o que poderia causar confusão no espectador. Se, por exemplo, no decorrer do filme, o ruído de um vaso sendo quebrado foi traduzido por onomatopeia, isso deveria ser traduzido dessa mesma forma ao longo de todo o filme. De forma análoga, é importante não utilizar a mesma onomatopeia para sons diferentes, por exemplo, a onomatopeia boum no filme é utilizada para caracterizar o ruído de pedras gigantes catapultadas, bem como por corpos que caem no chão. 
NASCIMENTO, Ana Katarinna do. As onomatopeias na legendagem para surdos e ensurdecidos do filme Asterix et Obelix.

Embora caiam com violência, a intensidade dos ruídos é diferente, mas o uso da mesma onomatopeia os equiparam...

2) Buscar utilizar onomatopeias conhecidas e de fácil compreensão. Como visto na seção sobre onomatopeias, elas buscam reproduzir na escrita o ruído que representam; no entanto, para os surdos e ensurdecidos, essa característica não facilita a compreensão do significado da onomatopeia se eles não conhecerem o som que representa. Sendo assim, a legenda deixaria de ser um auxílio para o espectador e se tornaria algo que deve ser decodificado pela imagem. Em casos de sons em off ${ }^{7}$, por exemplo, o input auditivo estaria perdido por uma legenda ineficiente.

3) Padronizar a ortografia das onomatopeias ao longo de todo o filme. Como se trata da forma escrita de um som, a ortografia das onomatopeias dependerá bastante de quem as escreve, embora hoje em dia muitas delas já estejam consolidadas. No entanto, sempre é possível acrescentar algumas letras aqui ou ali. É sabido que o espectador surdo tem nas LSEs, além de um meio para lazer, também uma forma de praticar a língua e desenvolver o vocabulário, já que consiste em sua segunda língua, segundo Araújo (2004). As diferentes grafias, além de atrapalhar a compreensão do filme, podem prejudicar a formação de vocabulário, pois eles podem não entender que se trata das mesmas onomatopeias e que estas possuem o mesmo significado, apesar de diferentes. No entanto, isso acarreta outro problema: o das diferentes alturas e gradação do som, pois na onomatopeia a intensidade pode ser aumentada e diminuída com a adição ou inserção de sílabas ou letras. Nesses casos, o ideal seria salientar essas diferenças em altura e intensidade em casos realmente extremos, como por exemplo em uma risada normal (ha ha ha) e uma risada bem exagerada, com a repetição de diversos ha.

4) Consultar glossários de onomatopeias. Sabe-se que a legendagem profissional requer prazos irrisórios, que muitas vezes não deixam tempo para uma pesquisa mais aprofundada. No entanto, muitos glossários on-line estão disponíveis para uma

\footnotetext{
${ }^{7}$ Sons cuja fonte não aparece na tela ao mesmo tempo em que é possível ouvi-lo.
} 
consulta rápida, permitindo que a onomatopeia mais apropriada ao contexto seja utilizada, com a ortografia mais recorrente.

Não é possível assegurar, com esses fatores, uma tradução de efeitos sonoros eficiente e sem erros, mas busca-se aperfeiçoa-la da melhor forma possível. Importante notar que ainda é preferível a tradução pela descrição do som, pois, além de ser mais conhecida do públicoalvo, ela não pressupõe o conhecimento de outro tipo de linguagem - a dos quadrinhos -, para fornecer o input do som, que é tão importante para a linguagem do cinema, algo ainda em desenvolvimento por grande parte do público surdo e ensurdecido.

Por fim, ressalta-se aqui a importância da acessibilidade audiovisual. Esta pesquisa não tem o intuito de inibir a prática de tornar acessível produtos audiovisuais, tais como filmes em mídia digital, mas de fomentar pesquisas a fim de melhorar continuamente esse tipo de tradução, para que o público-alvo tenha cada vez maior acesso a ele e de melhor qualidade.

\section{Referências}

ARAÚJO, Vera Lucia Santiago. Closed subtitling in Brazil. In: ORERO, P. (Ed.) Topics in audiovisual translation. Amsterdam: John Benjamins, 2004.

ASTÉRIX \& Obélix: mission Cleopatre. Direção: Alain Chabat. França, Itália: TF1 Films Productions. 2002. Disponível em: <http://streamcomplet.com/asterix-et-obelix-mission-cleopatre/>. Acesso em: 14 jul. 2015.

BAKER, Paul. Using Corpora in Discourse Analysis. Londres: Bloomsbury Academic, 2006.

BAKER, ROBERT ET AL. Handbook for Television Subtitlers. Winchester: University of Southampton and Independent Broadcasting Authority, 1984.

BIBE-LUYTEN, Sonia M. O que é história em quadrinhos. São Paulo: Brasiliense, 1985.

CIRNE, Moacy. A explosão criativa dos quadrinhos. Petrópolis: Vozes, 1970.

DÍAZ CINTAS, Jorge; REMAEL, Aline. Audiovisual translation: subtitling. Manchester: St. Jerome Publishing, 2007.

DIU, N. Un métier à découvir : adaptateur de programmes télévisés pour les sourds et malentendants. 2009. Disponível em: <http://www.semainedusoustitrage.org/IMG/pdf/Un_metiers_a_decouvrir.pdf >. Acesso em: 14 out. 2013. 
NASCIMENTO, Ana Katarinna do. As onomatopeias na legendagem para surdos e ensurdecidos do filme Asterix et Obelix.

GOSCINNY, René; UDERZO, Albert. Astérix et Cleopatre. Versão digital, 2014. Disponível em: http://flo.vas.free.fr/Ast\%E9rix\%20et\%20Ob\%E9lix\%20by\%20florentfr62/Ast\%E9rix\%20\%2006\%20-\%20Asterix\%20et\%20Cleopatre.pdf. Acesso em: 14 de jul. 2015.

LES ONOMATOPEES. Disponível em: < http://www.les-onomatopees.fr/>. Acesso em: 14 out. 2015.

NASCIMENTO, Ana Katarinna Pessoa do; TAGNIN, Stella Esther Ortweiler. A música e os ruídos na legendagem francesa para surdos e ensurdecidos. Letras \& Letras (Online), v. 30, p. 244-260, 2014.

NASCIMENTO, Ana Katarinna Pessoa do; ARAÚJO, Vera Lucia Santiago. Tradução de efeitos sonoros na legendagem para surdos e ensurdecidos. In: ZAVAGLIA, Claudia; STUPIELLO, E. N. A. Tendências contemporâneas dos estudos da tradução. São José do Rio Preto: UNESP, 2015. v. 2. Recurso eletrônico.

NEVES, Josélia. Audiovisual translation: subtitling for the deaf and hard of hearing. 2005. Tese (Doutorado) - Universidade de Surrey Roehampton, Inglaterra, 2005. Disponível em: <http:// rrp.roehampton.ac.uk/artstheses/1>. Acesso em: 15 jan. 2012.

ONOMATOPOEIA LIST. Disponível em: < http://www.onomatopoeialist.com/>. Acesso em: 14 out 2015.

Ana Katarinna Pessoa do Nascimento - Universidade de São Paulo - USP | São Paulo | São Paulo. Contato: katarinnapessoa@gmail.com 